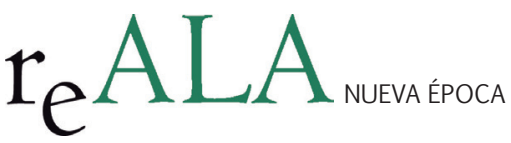

REALA, n 2, julio-diciembre 2014, ISSN: 1989-8975

DOI: http://dx.doi.org/10.24965/reala.voi2.10185

\title{
La nueva reforma de la Administración Local: principales cuestiones planteadas en el marco de su racionalización y sostenibilidad ${ }^{1}$
}

\author{
Juan Calvo Vérgez \\ Profesor Titular de Derecho Financiero y Tributario. Universidad de Extremadura \\ calvovergez@hotmail.com \\ Recibido: I 7 de abril 20I4 \\ Aceptado: 20 de junio 2014
}

\begin{abstract}
Resumen
El presente trabajo tiene por objeto analizar el alcance de la reforma de la Administración local operada por la nueva Ley 27/2013, de 27 de diciembre, de racionalización y sostenibilidad de la Administración Local, a través de la cual se persigue la consecución de los siguientes objetivos: clarificar las competencias municipales para evitar duplicidades con las competencias de otras Administraciones de forma que se haga efectivo el principio "una Administración una competencia"; racionalizar la estructura organizativa de la Administración local de acuerdo con los principios de eficiencia, estabilidad y sostenibilidad financiera; garantizar un control financiero y presupuestario más riguroso y favorecer la iniciativa económica privada evitando intervenciones administrativas desproporcionadas.
\end{abstract}

Palabras clave

Administración Local, reforma, municipios, Comunidades Autónomas, simplificación, duplicidad, control financiero.

\section{The New Local Government Reform: Key Issues Raised in the Context of Rationalization and Sustainability}

\section{Abstract}

This paper aims to analyze the scope of the reform of Local Government operated by the new Law 27/2013, of 27 December, rationalization and sustainability of local government, through which the achievement of the pursued following objectives: to clarify municipal powers to avoid duplication with the powers of other authorities so as to make effective the principle "one Administration, one competition"; rationalize the organizational structure of the local authority in accordance with the principles of efficiency, stability and sustainability financial; ensure a more rigorous financial and budgetary control and encourage private economic initiative avoiding disproportionate administrative interventions.

\section{Keywords}

Local Government, reform, municipalities, Autonomous Regions, simplification, duplicity, financial control.

1 El presente trabajo se enmarca en el Proyecto de Investigación "LA COORDINACIÓN FISCAL DESDE LA PERSPECTIVA DEL ORDENAMIENTO DE RÉGIMEN COMÚN” (DER2012-39342-C03-03) financiado por el Ministerio de Economía y Competitividad y cuyo Investigador Principal es el Prof. Dr. D. Juan Calvo Vérgez. 
SUMARIO

I. CONSIDERACIONES GENERALES. II. ALCANCE DE LA NUEVA DELIMITACIÓN COMPETENCIAL. III. EL PRETENDIDO REFORZAMIENTO DEL PAPEL DE LAS DIPUTACIONES PROVINCIALES. IV. MEDIDAS DESTINADAS A FOMENTAR LA FUSIÓN VOLUNTARIA DE MUNICIPIOS. V. LA PROHIBICIÓN DE PARTICIPACIÓN O DE CONSTITUCIÓN DE ENTIDADES INSTRUMENTALES POR LAS ENTIDADES LOCALES CUANDO ESTÉN SUJETAS A UN PLAN ECONÓMICO-FINANCIERO O A UN PLAN DE AJUSTE. VI. ALCANCE DEL CONJUNTO DE MEDIDAS DESTINADAS A LA RACIONALIZACIÓN ORGANIZATIVA E INTEGRACIÓN COORDINADA DE SERVICIOS. VII. EL REFORZAMIENTO DEL PAPEL DE LA FUNCIÓN INTERVENTORA EN LOS MUNICIPIOS. VIII. EL RÉGIMEN DE LOS FUNCIONARIOS DE LA ADMINISTRACIÓN LOCAL Y SUS LÍMITES RETRIBUTIVOS. IX. OTRAS REFORMAS DE INTERÉS. X. REFLEXIONES FINALES.

\section{CONSIDERACIONES GENERALES}

Con fecha 30 de diciembre de 2013 se publicó en el Boletín Oficial del Estado la Ley 27/2013, de 27 de diciembre, de racionalización y sostenibilidad de la Administración Local, después de casi diez meses de tramitación, ya que fue el 15 de febrero de 2013 cuando el Consejo de Ministros aprobó el Proyecto de Ley presentado inicialmente.

Con carácter general a través de la citada reforma se pretende ahorrar un total de 3.500 millones de euros, evitando duplicidades y clarificando las competencias de los Ayuntamientos. Asimismo se fija la competencia exclusiva e íntegra de la sanidad, la educación y los servicios sociales en las Comunidades Autónomas (CC.AA.) al objeto de desligarlas con una mayor precisión de las competencias locales.

Ya en su día la denominada Comisión para la Reforma de las Administraciones Públicas (CORA), creada mediante Acuerdo de Consejo de Ministros de 26 de octubre de 2012, comenzó a desarrollar una intensa labor de revisión integral de la Administración Pública destinada a conseguir una mejora en la eficacia y eficiencia de la actividad pública. En el seno de la CORA se han venido analizando e identificando aquellas actividades de gestión que, por ser similares o de la misma naturaleza, puedan desempeñarse dentro del ámbito de las distintas Administraciones Públicas de forma unificada o coordinada, aprovechando así, en mayor medida, los medios públicos. En esta misma línea se estimó prioritario impulsar y extender los sistemas de compras centralizadas para el aprovisionamiento del Sector público, con la finalidad de mejorar los procesos de contratación, racionalizar su gestión y, en última instancia, obtener ahorros.

Por su parte la Disposición Final Quinta del Real Decreto-Ley 8/2013, de 28 de junio, de Medidas Urgentes contra la Morosidad de las Administraciones Públicas y de Apoyo a Entidades Locales con Problemas Financieros, modificó el Texto Refundido de la Ley de Contratos del Sector Público (TRLCSP), aprobado mediante Real Decreto Legislativo 3/2011, de 14 de noviembre, estableciendo un nuevo régimen de competencias para la contratación centralizada². Asimismo la citada reforma se orientó hacia la centralización de los créditos de los expedientes que vayan a ser objeto de contratación centralizada, con la finalidad de permitir una mejor expresión de los ahorros obtenidos y simplificar la gestión presupuestaria. En este sentido dentro del conjunto de medidas propuestas por la CORA cabe destacar la relativa a la coordinación e integración del inventario de entes del Sector público estatal y de los sectores autonómico y local en un solo Inventario de Entes del Sector Público, con el objeto de incrementar y perfeccionar la información disponible y mejorar su ordenación y tratamiento.

El Proyecto de Ley de reforma de la Administración Local fue objeto además de un informe elaborado por la Comisión Nacional de la Competencia en el que se ponía de manifiesto la conveniencia de que las Entidades Locales optasen por fórmulas de gestión indirecta que permitan la prestación privada en servicios respecto de los cuales existe en la actualidad una reserva legal de actividad para los ayuntamientos tales como el abastecimiento domiciliario y depuración de aguas, la recogida, tratamiento y aprovechamiento de residuos o el transporte público de viajeros.

2 De cara al cumplimiento de dicha labor de forma eficaz, decidida y generalizada, mediante la aprobación del Real Decreto 696/2013, de 20 de septiembre, por el que se modifica el Real Decreto 256/2012, de 27 de enero, por el que se desarrolla la estructura orgánica básica del Ministerio de Hacienda y Administraciones Públicas, se creó la Dirección General de Racionalización y Centralización de la Contratación, cuya misión fundamental se concreta en el impulso, la gestión y el seguimiento de la contratación centralizada en el ámbito del Sector Público Estatal. Con carácter adicional el citado Real Decreto introdujo un conjunto de modificaciones en la estructura orgánica del Ministerio de Hacienda y Administraciones Públicas destinadas a clarificar las competencias de la Secretaría General de Coordinación Autonómica y Local, siendo encomendadas a esta última nuevos cometidos tales como la instrumentación y seguimiento de los mecanismos de financiación habilitados por la Administración General del Estado para las Comunidades Autónomas y las Entidades Locales, así como de los planes de ajuste acordados en este ámbito y la iniciación e instrucción de los procedimientos para la determinación y repercusión de las responsabilidades por incumplimiento del Derecho de la Unión Europea. 
Como seguramente se recordará la reforma del art. 135 de la Constitución española, en su redacción otorgada en 2011, consagró la estabilidad presupuestaria como principio rector que debe presidir las actuaciones de todas las Administraciones Públicas. En desarrollo de este precepto constitucional se aprobó la Ley Orgánica 2/2012, de 27 de abril, de Estabilidad Presupuestaria y Sostenibilidad Financiera, que exige nuevas adaptaciones de la normativa básica en materia de Administración local para la adecuada aplicación de los principios de estabilidad presupuestaria, sostenibilidad financiera o eficiencia en el uso de los recursos públicos locales.

Pues bien a tal efecto resultaba necesario adaptar determinados aspectos de la organización y funcionamiento de la Administración local así como mejorar su control económico-financiero. Y, transcurridos casi treinta años desde la entrada en vigor de la Ley 7/1985, de 2 de abril, reguladora de las Bases del Régimen Local (LBRL), y con más de una veintena de modificaciones de su texto original, a través de la nueva Ley 27/2013 se somete a una revisión profunda el conjunto de disposiciones relativas al completo estatuto jurídico de la Administración local.

La Ley 27/2013, de 27 de diciembre, persigue la consecución de los siguientes objetivos básicos: clarificar las competencias municipales para evitar duplicidades con las competencias de otras Administraciones de forma que se haga efectivo el principio "una Administración una competencia"; racionalizar la estructura organizativa de la Administración local de acuerdo con los principios de eficiencia, estabilidad y sostenibilidad financiera; garantizar un control financiero y presupuestario más riguroso y favorecer la iniciativa económica privada evitando intervenciones administrativas desproporcionadas.

En relación con el primero de los objetivos indicados con anterioridad, el relativo a la necesidad de clarificar las competencias locales y de avanzar en la correcta aplicación del principio "una Administración una competencia", se trata de evitar los problemas de solapamientos competenciales entre Administraciones hasta ahora existentes. A este respecto se ha de tener presente que la LBRL diseñó un modelo competencial que dio lugar al surgimiento de disfuncionalidades, generando en ocasiones situaciones de concurrencia competencial entre varias Administraciones Públicas, duplicidad en la prestación de servicios, y provocando que, en numerosas ocasiones, los Ayuntamientos presten servicios sin un título competencial específico que les habilite y sin contar con los recursos adecuados para ello, dando lugar así al ejercicio de competencias que no tienen legalmente atribuidas ni delegadas y a la duplicidad de competencias entre Administraciones.

Ciertamente el sistema competencial de nuestros municipios se configura como un modelo excesivamente complejo, del que se derivan dos consecuencias que inciden sobre planos diferentes. De una parte, dicho sistema competencial municipal hace que se difumine la responsabilidad de los Gobiernos locales en su ejercicio y se confunda con los ámbitos competenciales propios de otras Administraciones Públicas generando, en no pocas ocasiones, situaciones de inseguridad jurídica en la propia ciudadanía, que desconoce cuál es la Administración responsable de los servicios públicos. Y, de otra, cabe aludir a la existencia de una estrecha vinculación entre la disfuncionalidad del modelo competencial y las Haciendas locales. Debido a ello, y tal y como queda recogido en la Exposición de Motivos de la Ley 27/2013, se estima que, en un momento en el que el cumplimiento de los compromisos europeos sobre consolidación fiscal son de máxima prioridad, la Administración local también debe contribuir a este objetivo racionalizando su estructura, en algunas ocasiones sobredimensionada, y garantizando su sostenibilidad financiera.

El Tribunal Constitucional, a través de su Sentencia 233/1999, de 16 de diciembre, sin perjuicio de reconocer que el art. 149.1.18 CE es el precepto que ha de considerarse el título habilitante del Estado para ejercitar sus competencias sobre Haciendas locales cuando su regulación suponga introducir modificaciones de alcance general en el régimen jurídico de la Administración local o cuando se dicte en garantía de la autonomía que ésta tiene constitucionalmente garantizada (precisándose además que solo de manera puntual podrá el Estado regular con carácter exclusivo tal materia haciendo prevalecer el título competencial de la "Hacienda general" del art. 149.1.14 CE y recordando que las competencias son indisponibles e irrenunciables, tanto para el legislador del Estado como para el de las Comunidades Autónomas, operando ope Constitutionis, con independencia de que uno u otro legislador haga invocación explícita o errónea de las mismas), admitió la cita conjunta de los títulos competenciales recogidos en el art. 149.1.14 ${ }^{\mathrm{a}} \mathrm{CE}$ sobre Hacienda general y Deuda del Estado, y en el art. 149.1.18 de la Norma Fundamental sobre Bases del régimen jurídico de las Administraciones Públicas, justificando, con carácter limitado, la prevalencia del referido a la Hacienda General, en supuestos determinados. Así, por ejemplo, se encargó de precisar el supremo intérprete de nuestra Constitución que, dado que frecuentemente la regulación de la Hacienda local está llamada a incidir sobre dicho régimen jurídico, sólo de manera puntual podrá el Estado regular con carácter exclusivo tal materia haciendo prevalecer el otro título competencial a que hace referencia el art. 1.1 del Real Decreto Legislativo 2/2004, de 5 de marzo, por el que se aprueba el Texto Refundido de la Ley Reguladora de las Haciendas Locales (TRLRHL), esto es, el de la Hacienda general del art. 149.1.14 de la Constitución3.

3 Piénsese, por ejemplo, en aquellos casos en los que la normativa estatal tenga por objeto la regulación de instituciones comunes a las distintas Haciendas o de medidas de coordinación entre la Hacienda estatal y las Haciendas de las Corporaciones Locales, así como cuando 
De este modo la política presupuestaria de todos los poderes públicos, incluidos los locales, ha de adecuarse a los principios rectores de la Ley Orgánica 2/2012, de 27 de abril, de Estabilidad Presupuestaria y Sostenibilidad, dictada en desarrollo del art. 135 de la Constitución.

La Ley 27/2013 tiene como principal objeto modificar la Ley 7/1985, de 2 de abril, Reguladora de las Bases del Régimen Local, así como el Real Decreto Legislativo 2/2004, de 5 de marzo. Sin perjuicio de lo anterior se modifica la Ley 30/1992, de 26 de noviembre, de Régimen Jurídico de las Administraciones Públicas y del Procedimiento Administrativo Común (al objeto de incluir una nueva Disposición Adicional) y se derogan, entre otras, la Disposición Adicional Segunda y la Disposición Transitoria Séptima de la Ley 7/2007, de 12 de abril, del Estatuto Básico del Empleado Público.

La nueva Ley es de aplicación a la Comunidad Foral de Navarra en los términos establecidos en el art. 149.1.14 y $18^{\mathrm{a}}$ y Disposición Adicional Primera de la Constitución, sin perjuicio de las particularidades que resultan de la Ley Orgánica 13/1982, de 10 de agosto, de Reintegración y Amejoramiento del Régimen Foral de Navarra, y de la Disposición Final Tercera de la Ley Orgánica 2/2012, de 27 de abril, de Estabilidad Presupuestaria y Sostenibilidad Financiera. Asimismo la Ley 27/2013 se aplica a la Comunidad Autónoma del País Vasco en los términos establecidos en el art. 149.1.14. ${ }^{a}$ y 18. ${ }^{a}$ y Disposición Adicional Primera CE, sin perjuicio de las particularidades que resultan de la Ley Orgánica 3/1979, de 18 de diciembre, por la que se aprueba el Estatuto de Autonomía para el País Vasco, y de la Disposición Final Tercera de la Ley Orgánica 2/2012, de 27 de abril, de Estabilidad Presupuestaria y Sostenibilidad Financiera.

En el caso específico de Ceuta y Melilla sabido es que la organización y el funcionamiento de las instituciones de Gobierno de dichas Ciudades Autónomas se ha de adecuar a lo previsto en la Ley Orgánica 1/1995, de 13 de marzo, de Estatuto de Autonomía de Ceuta, así como a la Ley Orgánica 2/1995, de 13 de marzo, de Estatuto de Autonomía de Melilla, y a las normas de desarrollo que hayan sido dictadas en virtud de la potestad reglamentaria de sus respectivas Asambleas. Pues bien al amparo de lo dispuesto en la Ley 27/2013 corresponderá a dichas Ciudades Autónomas, en el marco de las citadas Leyes Orgánicas 1/1995, de 13 de marzo, de Estatuto de Autonomía de Ceuta, y 2/1995, de 13 de marzo, de Estatuto de Autonomía de Melilla, así como de las normas reglamentarias dictadas en su desarrollo, determinar la forma de gestión de los servicios públicos con respeto a los principios de estabilidad presupuestaria, sostenibilidad financiera, plurianualidad, transparencia, responsabilidad, lealtad institucional y eficacia en el uso de los recursos públicos. ${ }^{4}$

Las disposiciones de la nueva Ley son asimismo de aplicación a los municipios de Madrid y Barcelona, sin perjuicio de las particularidades de su legislación específica y con estricta sujeción a los principios de estabilidad presupuestaria y sostenibilidad financiera. Y sus previsiones se aplicarán respetando la organización comarcal en aquellas Comunidades Autónomas cuyos estatutos de autonomía tenga atribuida expresamente la gestión de servicios supramunicipales.

\section{ALCANCE DE LA NUEVA DELIMITACIÓN COMPETENCIAL}

Tal y como hemos señalado con anterioridad la Ley 27/2013 se inspira en los principios de "una Administración, una competencia", estabilidad, sostenibilidad y eficiencia, contemplando la posibilidad de que los Ayuntamientos de menos de 20.000 habitantes sean despojados de competencias en favor de las Diputaciones si no ajustan sus costes a una tabla que sería diseñada al efecto.

A tal efecto el legislador de la nueva Ley ha buscado modificar los arts. 25 y 26 de LBRL para eliminar competencias municipales tales como las relativas a la educación, la prestación de servicios sociales, la promoción y reinserción o actividades tales como promoción de la mujer o la sanidad, restándose a los Entes Locales la financiación correspondiente para estos servicios. Y ello con la finalidad de tratar de garantizar la dotación presupuestaria de cada uno de ellos.

Tomando como punto de partida el marco constitucional existente el Estado ha optado por ejercer su competencia de reforma de la Administración Local para tratar de definir con precisión las competencias que deben ser desarrolladas por aquélla, diferenciándolas de las competencias estatales y autonómicas. En este

su finalidad sea la salvaguarda de la suficiencia financiera de las Haciendas locales garantizada por el art. 142 CE, en cuanto que presupuesto indispensable para el ejercicio de la autonomía local constitucionalmente reconocido en los arts. 137, 140 y 141 de la Constitución.

4 En efecto, en el ámbito de las competencias enumeradas en el art. 21 de las citadas Leyes Orgánicas 1/1995 y 2/1995, de 13 de marzo, cuando no exista legislación sectorial estatal específica, las Asambleas de Ceuta y Melilla, en ejercicio de su potestad reglamentaria, podrán tipificar infracciones e imponer sanciones por el incumplimiento de deberes, prohibiciones o limitaciones de acuerdo con criterios mínimos de antijuridicidad basados en la intensidad de la perturbación, de los daños o del peligro causados. Las sanciones que puedan imponerse por la comisión de las conductas infractoras podrán consistir en multas o prohibiciones, por tiempo razonable y proporcionado, bien del ejercicio de actividades, incluso de las autorizadas o comunicadas, bien del acceso a equipamientos, infraestructuras, instalaciones o de la utilización de servicios públicos locales. 
sentido se enumera un listado de materias en las que, en todo caso, los municipios han de ejercer competencias propias, estableciéndose una reserva formal de ley para su determinación, así como una serie de garantías para su concreción y ejercicio.

A través de lo dispuesto en la Ley 27/2013 se estima que las Entidades Locales no deben volver a asumir competencias que no les atribuye la ley y para las que no cuenten con la financiación adecuada. Con carácter general solo podrán ejercer competencias distintas de las propias o de las atribuidas por delegación cuando no se ponga en riesgo la sostenibilidad financiera del conjunto de la Hacienda municipal y no se incurra en un supuesto de ejecución simultánea del mismo servicio público con otra Administración Pública. De igual modo, la estabilidad presupuestaria vincula de una forma directa la celebración de convenios entre administraciones y la eliminación de duplicidades administrativas. Por otra parte se estima que la delegación de competencias estatales o autonómicas en los Municipios debe ir acompañada de la correspondiente dotación presupuestaria, no siendo su duración inferior a los 5 años y reservándose la Administración que delega los mecanismos de control precisos para asegurar la adecuada prestación del servicio delegado.

Al hilo de la cuestión relativa a la asunción por parte de las Comunidades Autónomas de las competencias relativas a la educación, las normas reguladoras del sistema de financiación de las Comunidades Autónomas y de las Haciendas Locales fijarán los términos en los que las CC.AA. asuman la titularidad de las competencias que se prevén como propias del Municipio, aún cuando hayan sido ejercidas por éstas, por Diputaciones Provinciales o entidades equivalentes, o por cualquier otra Entidad Local, relativas a participar en la vigilancia del cumplimiento de la escolaridad obligatoria y cooperar con las Administraciones educativas correspondientes en la obtención de los solares necesarios para la construcción de nuevos centros docentes, así como la conservación, mantenimiento y vigilancia de los edificios de titularidad local destinados a centros públicos de educación infantil, de educación primaria o de educación especial, para lo que se contemplará el correspondiente traspaso de medios económicos, materiales y personales.

Respecto de la asunción por las Comunidades Autónomas de las competencias relativas a la salud, tras la entrada en vigor de la nueva Ley $27 / 2013$, y de acuerdo con las normas reguladoras del sistema de financiación autonómica y de las Haciendas Locales, las Comunidades Autónomas asumirán la titularidad de las competencias que se preveían como propias del Municipio, relativas a la participación en la gestión de la atención primaria de la salud. Dichos Entes Regionales asumirán la titularidad de estas competencias, con independencia de que su ejercicio se hubiese venido realizando por Municipios, Diputaciones Provinciales o entidades equivalentes, o cualquier otra Entidad Local.

En el plazo máximo de cinco años a contar desde la entrada en vigor de la Ley (que tuvo lugar el 31 de diciembre de 2013) las Comunidades Autónomas asumirán de forma progresiva, a través de un 20\% anual, la gestión de los servicios asociados a dichas competencias5. A estos efectos la Comunidad Autónoma elaborará un plan para la evaluación y reestructuración de los servicios. En todo caso la gestión por las Comunidades Autónomas de los servicios anteriormente citados no podrá suponer un mayor gasto para el conjunto de las Administraciones Públicas. Ahora bien lo anterior se ha de entender sin perjuicio de la posibilidad de las Comunidades Autónomas de delegar dichas competencias en los Municipios, Diputaciones Provinciales o entidades equivalentes, de conformidad con lo dispuesto por el art. 27 de la Ley 7/1985, de 2 de abril, reguladora de las Bases del Régimen Local.

Con carácter adicional, y de acuerdo con las normas reguladoras del sistema de financiación de las Comunidades Autónomas y de las Haciendas Locales, cada año que transcurra, dentro del periodo de cinco años anteriormente mencionado, sin que las CC.AA. hayan asumido el desarrollo del citado $20 \%$ de los servicios previsto al efecto o, en su caso, sin que hayan acordado su delegación, los servicios seguirán prestándose por el municipio, Diputación Provincial o entidad equivalente con cargo a la Comunidad Autónoma. Y en el supuesto de que ésta no transfiriese las cuantías precisas para ello se aplicarán retenciones en las transferencias que les correspondan por aplicación de su sistema de financiación, teniendo en cuenta lo que disponga su normativa reguladora.

En relación con la cuestión relativa a la asunción por las Comunidades Autónomas de las competencias relativas a servicios sociales, con fecha 31 de diciembre de 2015 la titularidad de aquellas competencias que inicialmente se preveían como propias del municipio, relativas a la prestación de los servicios sociales y de promoción y reinserción social, corresponderá a las Comunidades Autónomas, que podrán establecer a partir de ese momento las medidas que consideren necesarias para la racionalización del servicio. Las CC.AA. asumirán la titularidad de estas competencias, con independencia de que su ejercicio se hubiese venido realizando por los Entes Locales (que únicamente se encargarán de detectar y evaluar situaciones de necesidad y de la atención inmediata por exclusión social), Diputaciones Provinciales o entidades equivalentes, o por cualquier otra Entidad Local. En dicho plazo (de

5 Concretamente los municipios sólo se encargarán de la protección de la salubridad pública y de lo relacionado con los cementerios y servicios funerarios, siendo gestionadas las restantes materias por las Autonomías en un plazo de cinco años, si bien las CC.AA. deberán asumir un $20 \%$ anual de la gestión. 
dos años en el presente caso), y previa elaboración de un plan para la evaluación, reestructuración e implantación de los servicios, las CC.AA., en el ámbito de sus competencias, habrán de asumir la cobertura inmediata de dicha prestación.

Repárese en consecuencia que en estos dos últimos ámbitos (salud y servicios sociales) las CC.AA. cuentan con la alternativa de delegar el servicio en la Diputación o en el Ayuntamiento, si bien habrán de pagar por ello. Y, en el hipotético caso de que no lo hicieren, Hacienda les retendrá el equivalente de las transferencias del sistema de financiación. Por otra parte el traspaso de estas competencias no podrá suponer un incremento del gasto en su conjunto. En efecto la gestión por las Comunidades Autónomas de los servicios anteriormente citados no podrá suponer un mayor gasto para el conjunto de las Administraciones Públicas. Ello ha de entenderse no obstante sin perjuicio de la posibilidad de las Comunidades Autónomas de delegar dichas competencias en los municipios, Diputaciones Provinciales o entidades equivalentes, de conformidad con lo establecido en el art. 27 de la LBRL.

Al igual que señalábamos con anterioridad en relación con las competencias relativas a la educación, si a 31 de diciembre de 2015 las CC.AA. no hubieren asumido el desarrollo de los servicios de su competencia prestados por los municipios, Diputaciones Provinciales o entidades equivalentes, Entidades Locales, o, en su caso, no hubieren acordado su delegación, los citados servicios sociales seguirán prestándose por el municipio con cargo a la Comunidad Autónoma. Y en el supuesto de que la Comunidad Autónoma no transfiriera las cuantías precisas para ello se aplicarán retenciones en las transferencias que les correspondan por aplicación de su sistema de financiación, teniendo en cuenta lo que disponga su normativa reguladora.

Adviértase por tanto que se prolonga hasta el 31 de diciembre de 2015 el plazo para que las Comunidades Autónomas asuman competencias que con anterioridad eran propias del municipio sobre servicios sociales y reinserción social, contemplándose la posibilidad de retirar las competencias en servicios sociales a las Entidades locales y trasladar la responsabilidad de la asistencia a las Autonomías.

Desde nuestro punto de vista la presente reforma podría permitir a las CC.AA. rescatar servicios en la actualidad delegados tales como limpieza de colegios, consultorios médicos en pueblos pequeños, servicios de teleasistencia o guarderías, o bien cederlos a los Ayuntamientos a través de un convenio en el que se determine su coste y se asegure su financiación. Al objeto de poder retomar estas competencias las Comunidades Autónomas podrán disponer de un periodo de transición en el que se determinará quién y cómo se queda con estas responsabilidades. En efecto, se establece un plazo transitorio de cinco años para que las Comunidades Autónomas asuman competencias en educación y sanidad, que serán exclusivas de las Regiones y que, hasta la fecha, en algunos casos, ejercían los ayuntamientos de manera "impropia".

Cada competencia deberá estar correctamente financiada, de manera tal que si una concreta Administración cediese la gestión de un servicio a otra, habrá de pagarlo adecuada y puntualmente. La racionalización de la estructura organizativa proyectada ha de realizarse de conformidad con los principios de eficiencia, estabilidad y sostenibilidad, con un control financiero y presupuestario más riguroso. A tal efecto se establecen unos criterios de eficiencia y eficacia de obligado cumplimiento para las Entidades Locales, de forma tal que aquellos municipios de menos de 20.000 habitantes deberán ceder sus competencias a las Diputaciones cuando no aprueben el examen, si bien podrán recuperarlas si lo logran más adelante. En todo caso se prevé que las Diputaciones no puedan prestar ningún servicio antes local sin el beneplácito del ayuntamiento en cuestión.

La nueva Ley limita por tanto a los Ayuntamientos las competencias en servicios sociales. Únicamente aquellos municipios que tengan más de 20.000 habitantes están obligados a hacer frente a una reducida labor de "evaluación e información de situaciones de necesidad social y atención inmediata a personas en situación o riesgo de exclusión social”. 6

La Ley 27/2013 clasifica las competencias en propias (de prestación obligatoria o no en función de la población) e impropias (asumidas por otras Administraciones, aunque pueden ser delegadas a los Entes locales con la correspondiente financiación). Estas últimas únicamente podrán prestarse por los Entes Locales cuando esté garantizada la prestación de las primeras, siempre y cuando sean sostenibles financieramente y no se incurra en duplicidad. De este modo la Ley fija una relación de las competencias que la Comunidad Autónoma podrá delegar en un ayuntamiento de su territorio porque considere que éste va a prestar el servicio de manera más eficiente, para lo cual deberá traspasarle también la financiación necesaria para su prestación, al objeto de preservar el necesario respeto al principio de estabilidad presupuestaria. Con carácter adicional, tratándose exclusivamente de municipios con superávit, éstos podrán solicitar a su Comunidad Autónoma correspondiente permiso para prestar un servicio que haya detectado que ninguna otra Administración esté ofreciendo en su territorio.

6 Téngase presente a este respecto que, con anterioridad, en los municipios más pequeños (el 87\% del total) esta competencia se reconocía, si bien no resultaba de obligatoria aplicación. El resto de los servicios sociales recaían en la Administración autonómica. Como seguramente se recordará la LBRL atribuye a los Ayuntamientos competencias en "servicios sociales, promoción y reinserción social”, si bien las CC.AA. han ido asumiendo progresivamente dichas competencias en sus respectivos Estatutos. 
Por lo que respecta a las competencias propias, serán asumidas por las CC.AA. las de servicios sociales (salvo la evaluación e información de situaciones de necesidad social o atención inmediata por exclusión social), sanidad (excepto la protección de la salubridad pública y las relacionadas con cementerios y servicios funerarios) y educación (con la única excepción de la participación en el cumplimiento de la escolaridad obligatoria y de la cooperación con las administraciones educativas en la obtención de solares para la construcción de nuevos centros docentes).

En resumen, el legislador de la Ley 27/2013 procede a definir tanto las competencias propias de los Entes Locales como las delegadas, que deberán ser desarrolladas por la Administración Local, diferenciándolas de las competencias del Estado y de las Comunidades Autónomas. A tal efecto se alude a la potestad del Estado para delimitar las competencias municipales, disponiéndose la supresión de las competencias impropias o la obligación de formalizar convenios y de pagarlos para el traspaso de competencias y servicios entre Administraciones.

Refiriéndose a la cuestión relativa al mantenimiento de la reserva legal en favor de las Entidades Locales en determinados servicios se plantean CESTA LOÑO, HERNÁNDEZ DEL CASTILLO y PALMA FERNÁNDEZ7 hasta qué punto dicha reserva habría de compatibilizarse con el fomento de la competencia efectiva, procediéndose a potenciar la racionalidad y la competencia en las decisiones económicas de las Entidades Locales. En opinión de los citados autores, con la finalidad de lograr la apertura al mercado de la provisión efectiva de los servicios de titularidad local habría de preverse la obligación de las Entidades Locales de analizar ex ante determinados elementos a la hora de optar entre la gestión directa o indirecta, así como la opción por la gestión indirecta que permita la gestión privada siempre que concurran tales elementos. Asimismo, al objeto de fomentar la competencia en el acceso a la prestación de servicios sugieren dichos autores el establecimiento de procedimientos de selección competitivos bien diseñados y garantizar que los plazos contractuales no sean económicamente excesivos, restringiéndose las prórrogas y evitando las medidas que conlleven ventajas en el nuevo concurso. Finalmente, respecto de las privatizaciones parciales o totales de empresas públicas encargadas de la prestación de servicios públicos locales defienden estos autores que "La futura norma debería asegurar que, en aquellos casos en los que la entidad local optase por una estructura instrumental con participación pública y privada, tales privatizaciones se realicen de acuerdo con procesos de selección competitivos bien diseñados, que favorezcan, o al menos no restrinjan injustificadamente, la concurrencia empresarial y no limiten innecesaria, desproporcionada o discriminatoriamente el acceso a la condición de socio privado".

Para finalizar se ha de destacar el hecho de que la nueva normativa aprobada prevea que, en aquellos casos en los que el Estado, las Comunidades Autónomas o cualquier Entidad Local delegue el ejercicio de competencias en los municipios, dicha delegación deba ser aceptada expresamente por éstos, debiendo implicar además una mejora en la eficiencia de la gestión pública. No obstante será necesario limitar normativamente el recurso al convenio. 8

\section{EL PRETENDIDO REFORZAMIENTO DEL PAPEL DE LAS DIPUTACIONES PROVINCIALES}

A través de la aprobación de la Ley 27/2013 se persigue reforzar el papel de las Diputaciones Provinciales, Cabildos, Consejos insulares o entidades equivalentes. Esto se lleva a cabo mediante la coordinación por las Diputaciones de determinados servicios mínimos en aquellos municipios con población inferior a 20.000 habitantes o a través de la atribución a éstas de nuevas funciones tales como: la prestación de servicios de recaudación tributaria, administración electrónica o contratación centralizada en los municipios con población inferior a 20.000 habitantes; su participación activa en la elaboración y seguimiento en los planes económico-financieros; o la atribución de las labores de coordinación y supervisión, en colaboración con las Comunidades Autónomas, de los procesos de fusión de municipios.

En efecto, con la finalidad de racionalizar la estructura organizativa de la Administración Local se refuerza el papel de las Diputaciones provinciales permitiéndoles coordinar determinados servicios mínimos obligatorios de los municipios de menos de 20.000 habitantes, a menos que estos justifiquen que pueden prestarlos con un coste efectivo menor que el de aquéllas. Igualmente dichas Diputaciones asistirán a los municipios en las facultades de gestión de la recaudación tributaria, la gestión financiera, la administración electrónica y la contratación centralizada.

7 CUESTA LOÑO, P., HERNÁNDEZ DEL CASTILLO, A. y PALMA FERNÁNDEZ, J. L., “Por otros servicios públicos”, Diario Cinco Días (www.cincodias.com, consultada el 17 de junio de 2013).

8 Tal y como precisan CUESTA LOÑO, P., HERNÁNDEZ DEL CASTILLO, A. y PALMA FERNÁNDEZ, J. L., "Por otros servicios públicos”, Diario Cinco Días (www.cincodias.com, consultada el 17 de junio de 2013), dicha limitación ha de producirse al objeto de evitar una ausencia de tensiones competitivas en la figura y una insuficiente publicidad así como el surgimiento de problemas de información asimétrica que favorezcan al operador privado mejor situado o con mayor capacidad de capturar al decisor, en posible detrimento de los intereses de la Entidad Local, consumidores y usuarios y, finalmente, una excesiva discrecionalidad que pueda favorecer al operador privado. 
En aquellos casos en los que las dificultades financieras afecten a Ayuntamientos de menos de 20.000 habitantes (es decir, en la actualidad, a un total de 7.717 municipios, lo que representa el $95 \%$ del total) serán las Diputaciones, cabildos o consejos insulares quienes asuman la prestación de los servicios correspondientes. Por su parte los municipios de más de 20.000 habitantes podrán, además, ceder competencias a las Diputaciones si estimasen que así se mejora el servicio.

\section{MEDIDAS DESTINADAS A FOMENTAR LA FUSIÓN VOLUNTARIA DE MUNICIPIOS}

Por vez primera en el ámbito de la Administración Local, y como una de las principales novedades, la Ley 27/2013, de 27 de diciembre, de racionalización y sostenibilidad de la Administración Local, introduce diversas medidas concretas destinadas a fomentar la fusión voluntaria de municipios de forma que se potencie a aquellos municipios que se fusionen, ya que contribuyen a racionalizar sus estructuras y a superar la atomización del mapa municipal. Entre estas medidas de incentivo destacan, por ejemplo, las relativas al incremento de su financiación, la preferencia en la asignación de planes de cooperación local o de subvenciones o la dispensa en la prestación de nuevos servicios obligatorios como consecuencia del aumento poblacional.

Con carácter adicional, en el supuesto de que se acordase entre los municipios fusionados, alguno de ellos podría funcionar como forma de organización desconcentrada, lo que permitiría conservar la identidad territorial y denominación de los municipios fusionados aunque pierdan su personalidad jurídica. Estas medidas de fusiones municipales incentivadas, las cuales encuentran respaldo en lo dispuesto en la Sentencia del Tribunal Constitucional 103/2013, de 25 de abril9, supondrán que los municipios fusionados perciban un aumento de la financiación en la medida en que los municipios de menor población recibirán menos financiación.

En consecuencia la Ley 27/2013 incorpora un procedimiento de incentivos para los municipios que hipotéticamente se fusionen voluntariamente. Concretamente se establecen una serie de incentivos para el nuevo municipio fusionado tales como una mayor financiación per cápita, dispensa temporal para no prestar los nuevos servicios que pudieran resultar obligatorios por su aumento poblacional o una preferencia temporal en planes de cooperación local de infraestructuras, obras, servicios y subvenciones. Se fomentan así las fusiones municipales voluntarias de municipios que sean colindantes y que se encuentren dentro de la misma provincia a través de una mayor financiación per cápita, introduciéndose además una dispensa temporal para no prestar los nuevos servicios que pudieran resultar obligatorios por su aumento poblacional así como una preferencia temporal en planes de cooperación local de infraestructuras, obras, servicios y subvenciones. En todo caso se deja al Gobierno la potestad de vaciar de contenido político a aquellos municipios que no cumplan con las medidas de austeridad en aquellos casos en los que las liquidaciones que presente el Ayuntamiento ante el Ministerio de Hacienda sean negativas, así como si el nivel de endeudamiento sobrepasase los límites establecidos o si no siguiesen la normativa sobre estabilidad presupuestaria. En todos estos supuestos los municipios deberán someter sus servicios a examen. Tras un informe del interventor, el Ejecutivo podrá forzarles a suprimir "servicios facultativos" que no entren en sus competencias. En cuanto a los llamados "servicios obligatorios", éstos los pasarían a gestionar "indirectamente", sin capacidad de contratación. ${ }^{10}$

Por otro lado la Ley 27/2013 intensifica las trabas existentes a la creación y escisión de municipios, que deberán contar con, al menos, 5.000 habitantes. Las Entidades Locales de ámbito inferior al municipio deberán, en un plazo de tres meses, presentar sus cuentas ante el Estado y Comunidades Autónomas. En caso de que no lo hagan se disolverán y se integrarán en los ayuntamientos de los que dependan como organización desconcentrada, correspondiendo al municipio la prestación del mismo, carentes de personalidad jurídica. En todo caso no se permitirá la creación de nuevas Entidades Locales menores con personalidad jurídica propia y se mantendrán únicamente las existentes, si se presentan sus cuentas, y aquellas que hubiesen iniciado su procedimiento para su constitución antes del 1 de enero de 2013.

\section{LA PROHIBICIÓN DE PARTICIPACIÓN O DE CONSTITUCIÓN DE ENTIDADES INSTRUMENTALES POR LAS ENTIDADES LOCALES CUANDO ESTÉN SUJETAS A UN PLAN ECONÓMICO-FINANCIERO O A UN PLAN DE AJUSTE}

Como seguramente se recordará los antecedentes más inmediatos de la reestructuración del Sector público local son los acuerdos entre el Gobierno de la Nación y las Entidades Locales de 7 de abril de 2010 y de 25 de enero de 2012. El primero de ellos, definido como Acuerdo marco con las Entidades Locales sobre sostenibilidad de las finanzas públicas 2010-2013, estableció la aprobación por parte de dichas Entidades de un plan de racionalización de las estructuras de sus respectivos sectores públicos, administrativos y empresariales, con el objetivo de mejorar

9 Como es sabido dicha Sentencia fue dictada a la luz del recurso de inconstitucionalidad núm. 1523/2004 interpuesto por el Parlamento de Cataluña en relación con diversos preceptos de la Ley 57/2003, de 16 de diciembre, de medidas para la modernización del Gobierno Local.

10 A este respecto adquieren la consideración de servicios propios los de urbanismo, basuras, vías y obras, policía local, tráfico, ferias, cementerios, emergencia social, deporte, cultura y participación ciudadana. 
la eficiencia y reducir el gasto público. El segundo, definido como acuerdo de reordenación y racionalización del Sector público instrumental local y de control, eficiencia y reducción del gasto público gestionado por el mismo, tuvo como principal finalidad disciplinar la actividad de las Administraciones Públicas sin menoscabo de la calidad de los servicios que prestan. A tal efecto se tomaron como punto de partida las medidas de reducción de la dimensión del Sector público local, lo que implicaba la necesidad de controlar su actividad y racionalizar su organización.

Pues bien, partiendo de lo anterior el legislador de la Ley 27/2013 persigue tratar de impedir la participación o constitución de entidades instrumentales por las Entidades locales cuando estén sujetas a un plan económicofinanciero o a un plan de ajuste. En cuanto a las existentes que se encuentren en situación deficitaria se les exige su saneamiento y, en el hipotético caso de que éste no se produjese, se habría de proceder a su disolución. Por último se prohíbe, en todo caso, la creación de entidades instrumentales de segundo nivel, es decir, unidades controladas por otras, que, a su vez, lo estén por las Entidades locales. Esta prohibición, motivada por razones de eficiencia y de racionalidad económica, obliga a la disolución de aquellas entidades que ya existiesen a la entrada en vigor de la nueva norma en el plazo previsto.

Se prohíbe pues la creación de nuevas empresas públicas municipales. Y las ya existentes tendrán que disolverse, siempre y cuando sean deficitarias y no consigan volver a "números negros" antes del 31 de diciembre de 2014. En efecto, deberán disolverse aquellas estructuras holding y entidades dependientes que se encuentren en pérdidas, no pudiendo acometerse aportaciones para financiar déficits de explotación o la constitución de nuevas entidades mientras se encuentre en vigor un plan de saneamiento o de ajuste. Aquellas empresas municipales que no consigan financiar al menos el $51 \%$ de su presupuesto con los rendimientos de su actividad en el mercado tendrán que desaparecer.

Como no puede ser de otra manera esta racionalización del Sector público local obliga a realizar una revisión en profundidad del mismo y de sus organismos dependientes con la finalidad de racionalizar su número y estructura, lo que ha de generar ahorros importantes. Igualmente se limitan las retribuciones en los contratos mercantiles y de alta dirección del Sector público local, esto es, las retribuciones de los cargos públicos en función de la población del municipio (la máxima será equivalente a la de Secretario de Estado para los de más de 500.000 habitantes), y también las de los contratos mercantiles y de alta dirección"1. Lo mismo sucede además con el número tanto de cargos representativos locales que podrán ejercer sus funciones en régimen de dedicación exclusiva, como de personal eventual y en función de la población.

El número máximo de miembros del Consejo de Administración y de los órganos superiores de gobierno de estas entidades del Sector público local oscilará entre un mínimo de nueve y un máximo de quince. Dichas entidades incluidas en el Sector público local quedan obligadas a difundir a través de su página web la composición de sus órganos de administración, gestión, dirección y control, incluyendo los datos y experiencia profesional de sus miembros. Las retribuciones que perciban los miembros de estos órganos de dirección deberán recogerse anualmente en la memoria de actividades de la empresa o entidad pública local.

\section{ALCANCE DEL CONJUNTO DE MEDIDAS DESTINADAS A LA RACIONALIZACIÓN ORGANIZATIVA E INTEGRACIÓN COORDINADA DE SERVICIOS}

La Ley 27/2013 introduce un conjunto de medidas dirigidas a la racionalización organizativa e integración coordinada de servicios que, junto las ya previstas en el art. 21 de la Ley Orgánica de 2/2012, de 27 de abril, deberán incluirse en los planes económico-financieros de las Entidades Locales. A tal efecto se promueve la gestión integrada o coordinada de todos los servicios de los municipios de forma que, si generan unos ahorros mínimos, recibirán mayor financiación.

Inicialmente a través de la adopción de la citada reforma se perseguía reordenar competencias para evitar duplicidades entre las distintas Administraciones autonómicas y locales y mejorar la eficiencia en la prestación de los servicios mediante la introducción de un coste estándar al que habrían de ajustarse los Entes Locales a la hora de acometer la prestación de servicios. De cara al cálculo del citado "coste estándar" (el cual, a nuestro juicio, constituía un elemento esencial de la reforma entendido como forma de control del gasto municipal) se

11 En relación con estos dos últimos contratos dos son los sistemas retributivos a los que alude la nueva regulación, a saber, la retribución básica y la retribución complementaria. En relación con las primeras se señala que su fijación se producirá en función de las características de la entidad, siendo fijada así en atención a unos criterios ajenos a la tipología del contrato y de las funciones desarrolladas, incluyéndose una retribución mínima obligatoria asignada a cada máximo responsable, directivo o personal contratado. Por lo que a las segundas se refiere tiene lugar la fijación de un "complemento de puesto" con el que se retribuirán las características específicas de la función o puesto directivo, así como un "complemento variable" destinado a retribuir en función de unos objetivos previamente establecidos. En todo caso estas retribuciones tendrán fijado un límite máximo de retribución anual que vendrá determinado por la Ley de Presupuestos. Y dicho contrato de alta dirección en el Sector público local no generará derecho alguno a integrarse en la estructura de la Administración local de la que dependa la entidad del sector público en la que se prestasen tales servicios, más allá de los sistemas ordinarios de acceso al empleo público. 
tomaba en consideración el número de habitantes, la dispersión, las características del municipio y la densidad. Dicho coste, que habrían de publicar de manera obligatoria todos los ayuntamientos, permitiría a los ciudadanos conocer el coste real de cualquier servicio público. Una vez se conociese dicho coste, si éste fuese superior a la media, el mismo podría ser asumido por la Diputación siempre y cuando ésta pudiera prestar aquél por un coste más bajo. Se reforzaba así el papel de las Diputaciones a quienes, como órgano intermedio, les correspondería realizar funciones que se adscriben a esta Entidad Local.

Sin embargo la regulación del citado "coste estándar" fue puesta en tela de juicio en el Informe elaborado al respecto por el Consejo de Estado (al igual que sucedió con el recorte de la autonomía local planteado)12. Concretamente el citado Informe del Consejo de Estado alertó de que el texto inicial del Anteproyecto de Ley ponía en tela de juicio el art. 140 de la Constitución porque podía reducir "en exceso" la autonomía municipal garantizada por la Norma Fundamental. De conformidad con lo señalado en dicho Informe el citado "coste estándar” podía llegar convertirse en un "cheque en blanco" del Gobierno para quitar competencias a las Entidades Locales.

Finalmente dicho criterio del "coste estándar" fue sustituido por el del "coste efectivo", el cual únicamente obligará a los ayuntamientos a hacer público en un plazo tres meses el coste de sus servicios municipales. Con carácter general todas las Entidades Locales han de publicar y remitir al Ministerio de Hacienda y Administraciones Públicas el coste efectivo de sus servicios (ejercicio de competencias).

A nuestro juicio el nuevo "coste efectivo" aprobado se presenta como un elemento de transparencia destinado a reforzar los criterios de "publicidad y comparación", ya que ha de permitir a los ciudadanos conocer el coste de un servicio en su municipio y compararlo con entidades similares. De este modo la pérdida de competencias por parte de las Entidades locales quedaba finalmente eliminada del Proyecto de Ley. Únicamente aquellos municipios con problemas financieros en sus planes de ajuste económico-financieros podrían incluir la opción de "coordinar" determinadas funciones con las Diputaciones Provinciales, aunque continúen manteniendo la titularidad de la competencia. De este modo los ciudadanos podrán conocer el coste que tiene para su ayuntamiento prestar los servicios que reciban. En cambio el anterior "coste estándar" pretendía determinar para un mismo servicio (caso, por ejemplo, del abastecimiento de agua) un coste fijo predeterminado y que los municipios que no pudieran prestarlo a ese precio tuvieran que ceder la competencia a una Administración superior, normalmente la Diputación.

Con carácter anual, y antes del 1 de noviembre, las Entidades locales deberán calcular el coste efectivo de sus servicios, partiendo de la liquidación de sus presupuestos. El Ministerio de Hacienda facilitará a los Entes Locales unos criterios de cálculo en base a los cuales aquéllos puedan efectuar los cálculos oportunos, que habrán de ser debidamente comunicados al Ministerio. Y, tratándose de municipios de menos de 20.000 habitantes, éstos deberán delegar sus servicios básicos a las Diputaciones (o bien a la propia Comunidad Autónoma, si ésta fuera Uniprovincial), salvo que justifiquen que pueden prestar dichos servicios a un coste más bajo.

En todo caso estimamos que la introducción del criterio del "coste efectivo" contribuye igualmente a reforzar el papel de las Diputaciones, al otorgarse la competencia de vigilar la aplicación de los planes de ajuste municipales y de coordinar determinados servicios mínimos obligatorios de los municipios de menos de 20.000 habitantes mediante su prestación por la Diputación o la implantación de fórmulas de gestión compartida a través de consorcios, mancomunidades u otras fórmulas, a menos que el municipio justifique que puede prestar estos servicios con un coste efectivo menor que el de aquellas. Con carácter adicional las Diputaciones Provinciales podrán asistir a los municipios en las facultades de gestión de la recaudación tributaria, la gestión financiera, la Administración electrónica y la contratación centralizada.

Téngase presente además que el conjunto de Entes Locales asumen la obligación de publicar el coste que para ellos tiene prestar servicios tales como el alumbrado público, la retirada de basuras y limpieza viaria o el abastecimiento de agua en el plazo de tres meses. Y, cuando sean conocidos esos costes (que además permitirán comparar qué municipio ofrece el servicio más barato), en el supuesto de que éstos fuesen demasiado elevados, podrían ser asumidos por la Diputación correspondiente, siempre y cuando ofertase ese servicio a un coste menor. El llamado "coste efectivo" habrá de tener en cuenta además las singularidades de cada territorio y deberá hacerse público cada año.

En definitiva, como medida de transparencia la nueva Ley 27/2013 establece la obligación de determinar el coste efectivo de los servicios que prestan las Entidades Locales de acuerdo con criterios comunes, disponiéndose su remisión al Ministerio de Hacienda y Administraciones Públicas para su publicación. Esta medida constituye, a nuestro juicio, un paso fundamental en la mejora de la información disponible, eliminando asimetrías para la toma de decisiones de los ciudadanos y de la Administración, y contribuyendo de forma permanente al aumento de la

12 Véase a este respecto MARTín FERNÁNDEZ, J., "Reforma Local y finanzas”, en www.cincodias.com (consultada el 13 de septiembre de 2013), para quien la desaparición del concepto del "coste estándar" "se debe a una mala interpretación del dictamen del consejo de Estado y que vino a exigir que la configuración de sus elementos esenciales se fijara por ley". 
eficiencia. A tal efecto a través de la publicación agregada de la información de todos los costes efectivos de los servicios prestados por todas las Entidades Locales el Ministerio de Hacienda y Administraciones Públicas ha de contribuir a garantizar el cumplimiento del principio de eficiencia de conformidad con el art. 7 de la Ley Orgánica 2/2012.

\section{EL REFORZAMIENTO DEL PAPEL DE LA FUNCIÓN INTERVENTORA EN LOS MUNICIPIOS}

Con la finalidad de lograr un control económico-presupuestario más riguroso la Ley 27/2013 refuerza el papel de la función interventora en las Entidades Locales. De este modo se prevé que el Gobierno fije las normas sobre los procedimientos de control, metodología de aplicación, criterios de actuación, así como derechos y deberes en el desarrollo de las funciones públicas necesarias en todas las Corporaciones locales. Con ello se viene a cubrir un vacío legal existente, haciéndose posible la aplicación generalizada de técnicas tales como la auditoría en sus diversas vertientes, a las Entidades locales en términos homogéneos a los desarrollados en otros ámbitos del Sector público.

Para ello se contará con la participación de la Intervención General de la Administración del Estado. Asimismo, y con la finalidad de reforzar su independencia con respecto a las Entidades locales en las que prestan sus servicios los funcionarios con habilitación de carácter nacional, corresponde al Estado su selección, formación y habilitación así como la potestad sancionadora en los casos de las infracciones más graves. Se estima que la adopción de dicho planteamiento ha de implicar una mayor transparencia en la información económico financiera de las Entidades Locales, contribuyendo así a mejorar la toma de decisiones por los cargos electos en el ejercicio del mandato representativo que tienen encomendado constitucionalmente.

Ahora bien ello exigirá clarificar y deslindar el diferente ámbito de actuación que es consustancial a unas y otras funciones. Así, mientras que las propias del régimen de intervención y fiscalización quedan sujetas a parámetros de control y fiscalización interna de la gestión económico-financiera y presupuestaria, las correspondientes a la actuación del cargo electo quedan basadas necesariamente en aspectos de oportunidad o conveniencia.

En todo caso con la finalidad de garantizar un control financiero y presupuestario más riguroso la Ley 27/2013 procede a reforzar la función interventora, habilitando al Gobierno para establecer las normas sobre los procedimientos de control. Tal y como hemos tenido ocasión de analizar, y como contenido mínimo del Plan económico-financiero de las Entidades Locales que se encuentren en situación de déficit, se prevé la supresión de sus competencias impropias, incluyéndose una propuesta de fusión con otro municipio y gestionándose de forma integrada diferentes servicios para lo que contarán con la asistencia de las Diputaciones. Recuérdese a este respecto que, con carácter general, aquellos Entes Locales que se hallen en dificultades para seguir ejerciendo determinadas competencias sin incurrir en déficit deberán elaborar un plan económico-financiero que reconduzca sus cuentas hacia el equilibrio si bien, como se ha indicado, contarán con la posibilidad de solicitar ayuda a su Diputación para que sea ésta quien preste el servicio en mejores condiciones y a un menor coste, pudiendo también, alternativamente, iniciar el proceso de fusión con otros municipios. Ahora bien en ningún caso la Diputación podrá actuar de oficio sin el consenso previo del ayuntamiento con dificultades.

Aquellas Entidades Locales que desarrollen actividades económicas y que se hallen en desequilibrio financiero dispondrán de un plazo de dos meses desde la entrada en vigor de la Ley para aprobar, previo informe del órgano interventor de la Entidad Local, un plan de corrección de dicho desequilibrio. En el supuesto de que dicha corrección no se cumpliera a 31 de diciembre de 2014 la Entidad local, en el plazo máximo de los seis meses siguientes a contar desde la aprobación de las cuentas anuales o de la liquidación del Presupuesto del ejercicio de 2014, disolvería cada una de las Entidades que continuasen en situación de desequilibrio.

En definitiva, a 31 de diciembre de 2014 dichas entidades deberán presentar sus cuentas ante los organismos correspondientes del Estado y de la Comunidad Autónoma respectiva para no incurrir en causa de disolución. Su desaparición, en caso de no presentarlas, será acordada por Decreto del órgano de gobierno de la Comunidad Autónoma respectiva, en el que se podrá determinar su mantenimiento como forma de organización desconcentrada. La disolución en todo caso conllevará que el personal que estuviera al servicio de la entidad disuelta quede incorporado en el Ayuntamiento en cuyo ámbito territorial esté integrada. Además, en tal caso, el Ayuntamiento del que dependa la entidad quedará subrogado en todos sus derechos y obligaciones.

Adviértase en consecuencia que se trata un supuesto de disolución obligatoria. En el hipotético caso de que la Administración local no proceda a hacerlo así, dichas Entidades quedarán automáticamente disueltas el 1 de agosto de 2015. Con carácter adicional aquellos municipios menores de 5.000 habitantes que tengan un plan económico financiero en vigor y que lo incumplan al no rebajar su nivel de déficit o deuda serán intervenidos. Cuando ello suceda, el alcalde y los concejales del Ayuntamiento “díscolo” no cobrarán su sueldo. 


\section{EL RÉGIMEN DE LOS FUNCIONARIOS DE LA ADMINISTRACIÓN LOCAL Y SUS LÍMITES RETRIBUTIVOS}

En la línea de garantizar la profesionalidad y la eficacia de las funciones de control interno la Ley 27/2013 regula el régimen de los funcionarios de Administración local con habilitación de carácter nacional. De acuerdo con lo establecido en la Disposición Transitoria Undécima de la citada Ley, relativa a la aplicación de las limitaciones referidas al número de personal eventual y cargos públicos con dedicación exclusiva, a aquellas Entidades Locales que cumplan con los objetivos de estabilidad presupuestaria y deuda pública y cuyo período medio de pago a los proveedores no supere en más de 30 días el plazo máximo previsto de la normativa de morosidad, no les será de aplicación, con carácter excepcional, los límites previstos en los arts. 75 ter y 104 bis de la Ley 7/1985, de 2 de abril, reguladora de las Bases del Régimen Local hasta el 30 de junio de 2015. El cumplimiento de dichos requisitos será verificado por la Secretaría General de Coordinación Autonómica y Local del Ministerio de Hacienda y Administraciones Públicas, que, en virtud de la información comunicada por las Entidades Locales al mencionado Ministerio, publicará una lista de las Entidades Locales que cumplen los requisitos previstos antes indicados.

Dicha excepción podrá aplicarse a aquellas Entidades Locales que cumplan con los requisitos mencionados en el momento de la entrada en vigor de la nueva Ley y se mantendrá su aplicación hasta el 30 de junio de 2015 , en tanto sigan cumpliendo los requisitos mencionados. Ahora bien en ningún caso las Entidades Locales en las que concurran estos requisitos podrán incrementar el número total de puestos de trabajo de personal eventual o cargos públicos con dedicación exclusiva respecto al que disponían a 31 de diciembre de 2012.

Ciertamente uno de los principales objetivos perseguidos con la aprobación de la nueva Ley ha sido limitar el personal no funcionario de los municipios. En efecto, se limita el personal eventual de los Ayuntamientos según su tamaño y el número de cargos públicos con dedicación exclusiva, no pudiendo crearse Entidades de ámbito inferior al municipio con personalidad jurídica propia. No podrán pues crearse nuevos Entes locales de ámbito inferior al municipio, debiendo presentar los existentes sus cuentas ante el Estado y las Comunidades Autónomas en un plazo de tres meses. En otro caso quedarán disueltos.

Asimismo la Ley 27/2013 ha procedido a acotar la retribución de alcaldes y concejales, la cual habría de oscilar entre 100.000 y 30.000 euros, según el tamaño de cada localidad, incluyendo todos los conceptos salariales. Concretamente al amparo de un primer borrador facilitado por el Ejecutivo los 4.673 municipios que tuviesen menos de 1.000 habitantes no podrían pagar a los cargos electos ni habría dedicaciones exclusivas, si bien podrían recibir dietas por asistencia a Plenos, algo que en la práctica ya sucede en la mayoría de los casos. Asimismo se establecería como tope el sueldo de un Secretario de Estado (de unos 100.000 euros gracias a los complementos) para los regidores de los seis municipios españoles con más de medio millón de habitantes. Aquellos municipios con una población de entre 300.000 y medio millón de habitantes tendrían como techo esa referencia, menos un 10\%. Y así sucesivamente, adoptando el criterio de a menor población menos sueldo.

De este modo se procedía a limitar el número de cargos públicos con dedicación exclusiva, así como el sueldo de los alcaldes y concejales, con el tope del salario correspondiente a un Secretario de Estado. Igualmente se establecerían límites retributivos para los gerentes de Entidades Locales, afirmándose a este respecto en el Proyecto de Ley que "Se incluye (...) una ordenación responsable de las retribuciones del personal al servicio de las Corporaciones Locales (...) cualquiera que sea la naturaleza jurídica de su relación con la Administración”. Y no cobrarán los alcaldes de localidades con menos de mil habitantes.

Se fijaban pues límites establecidos en función de criterios poblacionales al número de cargos representativos locales que podrían ejercer sus funciones en régimen de dedicación exclusiva y el número de personal eventual al servicio de las Entidades Locales, el cual no podría superar un determinado número en función de la población del municipio. De este modo el Estado venía a asumir un importante control retributivo en la Administración y en el Sector público local, restringiéndose la figura del personal eventual entendida como fórmula de exclusiva prestación de servicios para la Entidad local, los cuales habrán de prestarse exclusivamente en los "servicios generales" de cada Entidad local.

En relación con la cuestión relativa a la prestación de servicios en la Administración Local, se introduce un nuevo art. 92.2 de la Ley de Bases de Régimen Local, de conformidad con el cual "Con carácter general, los puestos de trabajo en la Administración Local y sus Organismos Autónomos serán desempeñadas por personal funcionario". Por su parte el art. 92.3 de la Ley establece una reserva de funciones para este colectivo, efectuándose una traslación del art. 9.2 y del primer párrafo de la Disp. Adic. $2^{\text {a }}$ del Estatuto Básico del Empleado Público ${ }^{13}$. Tal y como

13 Señala concretamente este nuevo precepto que "Corresponde exclusivamente a los funcionarios de carrera al servicio de la Administración local el ejercicio de las funciones que impliquen la participación directa o indirecta en el ejercicio de las potestades públicas o en la salvaguardia de los intereses generales. Igualmente son funciones públicas, cuyo cumplimiento queda reservado a funcionarios de carrera, las que impliquen ejercicio de autoridad, y en general, aquellas que en desarrollo de la presente Ley, se reserven a los funcionarios para la mejor garantía de la objetividad, imparcialidad e independencia en el ejercicio de la función." 
ha precisado BOLTAINA BOSCH${ }^{14}$ se recupera "la vieja dicción del antiguo art. 92 de la LBRL -sustituido precisamente por el EBEP- de que se reservará en todo caso a los funcionarios aquellos puestos que impliquen una 'mejor garantía de la objetividad, imparcialidad e independencia en el ejercicio de la función"”.

A la hora de delimitar el nuevo modelo retributivo del personal de los Entes Locales, relativo a los miembros de las Corporaciones Locales y al personal al servicio de las Entidades Locales (a pesar de tratarse de regímenes jurídicos completamente diferentes), el Proyecto de Ley procedió inicialmente a fijar los límites retributivos totales anuales para los miembros de las Corporaciones locales derivando a la Ley de Presupuestos Generales del Estado la concreción de los mismos ${ }^{15}$. Tal y como se ha señalado con anterioridad por el conjunto de los conceptos retributivos y asistencias en ningún caso se podría superar la retribución de un Secretario de Estado de la Administración General del Estado, procediéndose a partir de dicho límite a reducir el porcentaje en un 10\% (hasta alcanzar un $80 \%$ ) en función del tramo de población del municipio, y fijándose también la retribución total máxima a percibir por los Presidentes de las Diputaciones Provinciales, que quedaría subordinada, como máximo, a la retribución del alcalde del municipio más poblado de su provincia.

Asimismo fue objeto de regulación el régimen de dedicación exclusiva prohibiéndose en determinados supuestos (caso, por ejemplo, de los municipios de población inferior a 1000 habitantes) el régimen de incompatibilidad de estas dedicaciones si coincidiese el cargo electo con su elección como diputado provincial y el régimen de asistencias, que sólo correspondería a aquel electo que no gozase ni de dedicación exclusiva ni parcial.

En relación con el nuevo régimen retributivo de los empleados públicos locales el apartado cuarto de la Disp. Adic. Séptima del Proyecto de Ley tomaba como referencia el marco de la Ley Orgánica de Estabilidad Presupuestaria de 2012 así como el art. 93.2 de la LBRL, estableciendo que "Las retribuciones complementarias se atendrán, asimismo, a la estructura y criterios de valoración objetiva de las del resto de los funcionarios públicos. Su cuantía global será fijada por el Pleno de la Corporación dentro de los límites máximos y mínimos que se señalen por el Estado". ${ }^{16}$

Añadía a continuación el citado precepto que correspondería exclusivamente al Estado, a través de la Ley de Presupuestos, fijar la horquilla retributiva. La Ley de Presupuestos podría establecer un límite máximo y mínimo total en las percepciones del personal funcionario y laboral de las Administraciones Locales, superando así el ámbito de aplicación del art. 93.2 de la LBRL, que se refiere exclusivamente a las retribuciones complementarias. Dichos límites máximos y mínimos lo serían por todos los conceptos retributivos que pudieran percibirse por los empleados locales de las Entidades Locales y de entidades de ellas dependientes en función del grupo de clasificación profesional, así como de otros factores que se puedan determinar cada año en la Ley de Presupuestos Generales del Estado. En todo caso tuvo lugar la fijación de un límite máximo por todos los conceptos retributivos, lo que debía interpretarse como comprensivo del complemento de antigüedad. Dicho máximo anual a percibir se vinculaba además en función del grupo de clasificación profesional y de otros factores que pudieran determinarse en las Leyes de Presupuestos Generales del Estado de cada año.

Finalmente, y tras la aprobación de la Ley 27/2013, aquellos municipios que tengan al día sus cuentas y cumplan con la Ley de Morosidad no tendrán que aplicar hasta el 30 de junio de 2015 la limitación legal en personal eventual y cargos públicos con dedicación exclusiva. Los ediles de pueblos entre 1.000 y 2.000 habitantes podrán cobrar como máximo el 30\% de lo que ingresa un secretario de Estado (unos 20.100 euros brutos anuales). En el arranque de la tramitación parlamentaria ese salario se limitaba a 13.400 euros. Finalmente, y tras la aprobación de una Enmienda en el Senado, se dispuso que el techo se situase en 40.000 euros. De este modo, y tomando siempre como referencia la retribución de los Secretarios de Estado, el techo salarial para los ediles que presten sus servicios en municipios de 5.001 a 10.000 habitantes pasó de 40.000 euros como máximo a 45.000 euros. Y los de entre 10.001 y 20.000 habitantes podrán ingresar como tope un $5 \%$ más que lo que dictaba el Proyecto inicial.

Por lo que respecta a los alcaldes de municipios de menos de 1.000 habitantes, a pesar de que no podrán disfrutar de dedicación exclusiva, excepcionalmente podrán desempeñar sus cargos con dedicación parcial, percibiendo sus retribuciones dentro de los límites máximos señalados en la Ley de Presupuestos Generales. A tal

14 BOLTAINA BOSCH, X., "La reforma del régimen local y la posible modificación, limitación o reducción de las retribuciones de los empleados públicos”, Revista Aranzadi Doctrinal, núm. 5, 2013 (Consultado en www.westlaw.es). Tal y como afirma el citado autor la nueva redacción resulta "poco respetuosa con un esquema lógico de normativa sobre empleo público al dar preeminencia a una norma ajena al mismo, sino referida a la administración local, y también subordinar la legislación de función pública autonómica a lo que se fije en la nueva LBRL".

15 Ello es así a pesar de que cada Comunidad Autónoma, de acuerdo con lo dispuesto de manera expresa en el Estatuto Básico del Empleado Público, goza de un amplio margen legislativo para establecer su marco retributivo.

16 En relación con el alcance de la citada regulación señala BOLTAINA BOSCH, X., "La reforma del régimen local y la posible modificación, limitación o reducción de las retribuciones de los empleados públicos”, ob. cit., que la citada regulación "unifica a todas las Entidades Locales, sin importar su estado real financiero ni su realidad específica; porque orilla por completamente los criterios de política de recursos humanos reduciendo toda la intervención a un criterio economicista, y porque finalmente, la inconcreción es tal, que queda todo en una imprecisión jurídica muy significativa". 
efecto los baremos habrán de quedar referenciados al salario de un Secretario de Estado, cuyo bruto anual en los últimos Presupuestos Generales del Estado es de 68.363 pero que, como se ha señalado con anterioridad, junto al complemento de productividad, ronda los 100.000 euros.

\section{OTRAS REFORMAS DE INTERÉS}

Con la finalidad de favorecer la iniciativa económica privada evitando intervenciones administrativas desproporcionadas, se limita el uso de autorizaciones administrativas para iniciar una actividad económica a casos en los que su necesidad y proporcionalidad queden claramente justificadas. Así las cosas, y al objeto de fomentar la actividad económica local, el ejercicio de actividades por parte de los Entes Locales no se someterá a la obtención de licencia, salvo en los casos en los que su necesidad y proporcionalidad queden claramente justificadas. Asimismo se suprimen monopolios que venían heredados del pasado, como lonjas y mercados y que recaen sobre sectores económicos pujantes en la actualidad.

En relación con la mayoría requerida para la adopción de acuerdos en las Corporaciones Locales se señala, a través de la introducción de una nueva Disposición Adicional Decimosexta que, excepcionalmente, cuando el Pleno de la Corporación Local no alcance, en una primera votación, la mayoría necesaria para la adopción de acuerdos prevista en la nueva Ley, la Junta de Gobierno Local tendrá competencia para aprobar: el presupuesto del ejercicio inmediato siguiente, siempre que previamente exista un presupuesto prorrogado; los planes económicofinancieros, los planes de reequilibrio y los planes de ajuste a los que se refiere la Ley Orgánica 2/2012, de 27 de abril; los planes de saneamiento de la Corporación Local o los planes de reducción de deudas; y la entrada de la Corporación Local en los mecanismos extraordinarios de financiación vigentes a los que se refiere la Ley Orgánica 2/2012, de 27 de abril, y, en particular, el acceso a las medidas extraordinarias de apoyo a la liquidez previstas en el Real Decreto-ley 8/2013, de 28 de junio, de medidas urgentes contra la morosidad de las administraciones públicas y de apoyo a entidades locales con problemas financieros.

En todo caso la Junta de Gobierno Local dará cuenta al Pleno en la primera sesión que se celebre con posterioridad a la adopción de los acuerdos mencionados, los cuales serán objeto de publicación de conformidad con las normas generales que les resulten de aplicación.

Respecto de las Mancomunidades de municipios se señala en la Disp. Transit. $11^{\text {a }}$ de la Ley que, en el plazo de seis meses a contar desde la entrada en vigor de la Ley 27/2013, las mancomunidades de municipios deberán de adaptar sus estatutos a lo previsto en el art. 44 de la Ley 7/1985 para no incurrir en causa de disolución. Las competencias de las mancomunidades de municipios estarán orientadas exclusivamente a la realización de obras y la prestación de los servicios públicos que sean necesarios para que los municipios puedan ejercer las competencias o prestar los servicios enumerados en los arts. 25 y 26 de la Ley 7/1985, de 2 de abril, reguladora de las Bases de Régimen Local. El expediente para la disolución será iniciado y resuelto por el Órgano de Gobierno de la Comunidad Autónoma, y en todo caso, conllevará que el personal que estuviera al servicio de la mancomunidad disuelta quede incorporado en las Entidades Locales que formaran parte de ella de acuerdo con lo previsto en sus estatutos y que las Entidades Locales que formen parte de la mancomunidad disuelta queden subrogadas en todos sus derechos y obligaciones.

En cuanto a las mancomunidades y a otros organismos intermedios ya existentes que tampoco cumplan dichos requisitos de eficiencia, se prevé que dichos entes desaparezcan, no siendo posible la creación de otros nuevos. La principal finalidad de dicha medida no es otra que reforzar las competencias de las Diputaciones Provinciales, al objeto de tratar de convertir a éstas en centrales de servicios y de compras, al considerar que así se ahorrarán también costes. Recuérdese a este respecto que, tal y como ya se ha precisado, la presente reforma persigue otorgar un mayor poder a las Diputaciones, las cuales asumirían directamente la prestación de servicios de los municipios que no respeten el equilibrio presupuestario o que gasten más de lo que deben o se endeuden por encima de lo que marca la ley. Aquellos Ayuntamientos en dificultades económicas con más de 20.000 habitantes seguirían prestando los servicios indirectamente, sin poder político sobre la gestión de los mismos (por ejemplo, en la contratación). Los servicios de las mancomunidades pasarán un examen, pudiendo llegar a desaparecer en el supuesto de que no alcancen unos niveles de eficiencia. Concretamente las mancomunidades y las Entidades Locales menores deberán rendir cuentas en tres meses, y las que no lo hagan desaparecerán.

Para finalizar queremos referirnos de manera específica a la modificación operada del Real Decreto Legislativo 2/2008, de 20 de junio, por el que se aprueba el Texto Refundido de la Ley de Suelo (TRLS), a cuyo art. 39 se incorporó un nuevo apartado quinto. A resultas de una Enmienda introducida por el Grupo Parlamentario Popular se permite a los Entes Locales destinar suelo a reducir deuda de forma excepcional y con determinadas condiciones, debiendo reponer el importe de ese suelo en un plazo máximo de diez años.

A través de la introducción de dicha Enmienda se persiguió que los Ayuntamientos cuenten con una herramienta más para reducir su deuda que asciende a 43.153 millones de euros, según los últimos datos del 
Banco de España referentes a junio de 2013. A tal efecto la citada Enmienda vino a modificar el TRLS y añadió un nuevo apartado por el que los ayuntamientos podrán destinar el terreno público "a reducir la deuda comercial y financiera". Con anterioridad a la introducción de la presente reforma dichos solares sólo se podían utilizar para fines como la construcción de vivienda protegida o dotaciones públicas (colegios, centros de salud, parques, etc.). Este nuevo uso del suelo público se hará "excepcionalmente" y con condiciones, a saber: haber aprobado el Presupuesto de la Entidad Local del año en curso y liquidado los de los ejercicios anteriores; tener el Registro del patrimonio municipal del suelo correctamente actualizado; que el Presupuesto municipal tenga correctamente contabilizadas las partidas del patrimonio municipal del suelo; que exista un Acuerdo del Pleno de la Corporación Local en el que se justifique que no es necesario dedicar esas cantidades a los fines propios del patrimonio público del suelo y que se van a destinar a la reducción de la deuda de la Corporación Local, indicando el modo en que se procederá a su devolución; y que se haya obtenido la autorización previa del órgano que ejerza la tutela financiera.

El importe del que se disponga deberá ser repuesto por la Corporación Local en un plazo máximo de diez años, de acuerdo con las anualidades y porcentajes fijados por Acuerdo del Pleno para la devolución al patrimonio municipal del suelo de las cantidades utilizadas. Por su parte los Presupuestos de los ejercicios siguientes al de adopción del Acuerdo deberán recoger, con cargo a los ingresos corrientes, las anualidades citadas. Todo ello con el objetivo último de reducir la deuda en un momento de paralización del mercado inmobiliario y de un amplísimo parque de viviendas pendiente de venta y a precios reducidos.

De este modo, y a resultas de la introducción de la citada Enmienda, aquellos municipios que dispongan de un patrimonio público de suelo (para vivienda protegida y equipamientos) podrán destinarlo a reducir la deuda comercial y financiera. Con carácter general se prevé que esta vía para amortizar deuda, que en el caso de las Corporaciones Locales se eleva en la actualidad a 43.153 millones de euros, beneficie sobre todo a los Ayuntamientos donde más se ha construido en la época del boom inmobiliario y que, por consiguiente, tienen un mayor patrimonio por las cesiones obligatorias de los promotores privados.

Se autoriza pues a los municipios para destinar al pago de la deuda el suelo que con anterioridad se dedicaba a construir Viviendas de Protección Oficial o a otros usos sociales (colegios, centros de salud, zonas verdes), siempre y cuando se cumplan unos requisitos. A pesar de que nada se señaló en la Enmienda acerca de cómo se ha de realizar la amortización, parece razonable considerar que las parcelas puedan subastarse para conseguir liquidez. Con carácter adicional aquellos Entes Locales que quieran acceder a esta medida deberán cumplir unos requisitos adicionales tales como tener un registro del patrimonio municipal del suelo actualizado y que el presupuesto contabilice correctamente las partidas del patrimonio o que se tenga la autorización de Hacienda. Los Plenos de las Corporaciones Locales deberán justificar que no es necesario dedicar ese suelo a fines sociales, quedando obligados a reponerlo en el plazo de diez años de acuerdo con un calendario anual. Ahora bien nada se señala acerca de las consecuencias que pudieran llegar a derivarse de un eventual incumplimiento.

\section{REFLEXIONES FINALES}

La aprobación de la nueva Ley 27/2013, de 27 de diciembre, de racionalización y sostenibilidad de la Administración Local, persigue la consecución de los siguientes objetivos básicos: clarificar las competencias municipales para evitar duplicidades con las competencias de otras Administraciones de forma que se haga efectivo el principio "una Administración una competencia”; racionalizar la estructura organizativa de la Administración local de acuerdo con los principios de eficiencia, estabilidad y sostenibilidad financiera; garantizar un control financiero y presupuestario más riguroso y favorecer la iniciativa económica privada evitando intervenciones administrativas desproporcionadas.

Desde nuestro punto de vista lo esencial en relación con la nueva reforma es que se alcance una delimitación clara de la relación existente entre las diferentes Administraciones a la hora de prestar los servicios, sobre todos aquellos que les deleguen las Comunidades Autónomas. Debe alcanzarse un reparto competencial suficientemente adecuado en base al cual los Entes Locales presten únicamente aquellos servicios que les correspondan de conformidad con lo establecido en la Ley Reguladora de Bases de Régimen Local, sin merma de sus recursos financieros y sin incurrir en déficit. Y ello con el objetivo de otorgar estabilidad a la delegación de competencias y garantizar la financiación.

Estimamos que la reforma operada únicamente podrá ser valorada positivamente si logra evitar duplicidades administrativas así como reforzar el control financiero de las Entidades locales y favorecer el desarrollo de la iniciativa privada. 
